\title{
A circulação internacional dos cientistas brasileiros nos primeiros anos do CNPq (1951-1955)
}

\author{
The international circulation of Brazilian scientists in the early years \\ of CNPq (1951-1955)
}

\author{
ALEX GONÇALVES VARELA \\ Museu de Astronomia e Ciências Afins | MAST \\ HELOISA MARIA BERTOL DOMINGUES \\ Museu de Astronomia e Ciências Afins | MAST \\ CARLOS ALBERTO COIMBRA \\ Museu de Astronomia e Ciências Afins | MAST
}

RESUMO O objetivo central deste artigo consiste em analisar a política de circulação internacional dos cientistas elaborada nos primeiros anos do CNPq, pelo então presidente Álvaro Alberto, o primeiro a presidir o Conselho. Este texto é apenas uma tentativa preliminar de apresentar os dados iniciais levantados sobre as bolsas e auxílios concedidos a pesquisadores brasileiros rumo ao exterior, seja para realizar o doutoramento, participar de congressos científicos ou fazer estágios em laboratórios, bem como a cientistas estrangeiros que vieram para cá lecionar e realizar pesquisas em nossas instituições, formar pesquisadores ou proferir palestras. O que nos interessa é a circulação internacional dos cientistas, e a sua formação em última instância para o desenvolvimento da ciência e da tecnologia no Brasil.

Palavras-chaves $\mathrm{CNPq}$ - Álvaro Alberto - circulação internacional - cientistas - bolsas e auxílios.

\begin{abstract}
The central purpose of this article is to analyze the policy of international circulation of scientists developed in the first years of CNPq, by then President Álvaro Alberto, the first to chair the Council. This text is only a preliminary attempt to present the initial data collected on scholarships and grants awarded to Brazilian researchers towards the outside, or to make a doctorate, participate in scientific meetings or do internships in laboratories as well as foreign scientists who came to here to teach and conduct research at our institutions, train researchers or lecture. What interests us is the international circulation of scientists, and their formation to the development of science and technology in Brazil.
\end{abstract}

Keywords CNPq-Álvaro Alberto - international circulation-scientists - scolarships and grants. 


\section{Introdução}

No início de sua história, ou seja, no período que permeia os anos de 1951 a 1955, o Conselho Nacional de Pesquisas (CNPq) foi dividido pelas políticas econômicas e de relações internacionais. ${ }^{1}$ Esta segunda é a que nos interessa para este estudo. Uma das atividades de fomento do órgão era o apoio ao intercâmbio científico no país e no exterior. A criação do Conselho ampliou as possibilidades de formação no exterior, intensificando a circulação internacional de pesquisadores nacionais que foram estudar em instituições estrangeiras, obtendo títulos, diplomas e competências, tal como a vinda de cientistas estrangeiros ao país para a realização de atividades de pesquisa e ensino, contribuíram para intensificar o intercâmbio entre pesquisadores e instituições dos países ocidentais.

Temos como propósito analisar a política de circulação internacional dos cientistas, quer sejam brasileiros que emigraram para o exterior, ou estrangeiros que para cá imigraram, elaborada nos primeiros anos do CNPq, pelo então presidente Álvaro Alberto. Este teve uma atuação ímpar para a criação e constituição do órgão, e foi o primeiro presidente a dirigi-lo por um período de quase cinco anos (1951-1955). Neste último ano, pediu demissão do Conselho, em março, e, ainda no referido ano, outro presidente assumiu a instituição: José Baptista Pereira (março de 1955 a fevereiro de 1956).

\section{Um breve histórico da circulação internacional de estudiosos no Brasil}

Durante a época colonial, a possibilidade de formação no exterior era um privilégio das famílias abastadas. As instituições universitárias mais procuradas pelos estudantes "brasileiros" foram Montpellier, na França, e Coimbra, em Portugal. Ganhavam destaque as faculdades de Medicina, Filosofia e Leis. Estes estudos eram subvencionados pelas próprias famílias dos estudantes. ${ }^{2}$

Com a realização da Independência do Brasil, os intercâmbios científicos foram intensificados. Diversos cientistas de distintas nacionalidades para cá vieram, quer integrando expedições - como Charles Frederic Hartt, que foi nomeado para ser o chefe da Comissão Geológica do Brasil, e Orville Adelbert Derby, que atuou no Museu Imperial e foi nomeado chefe da Comissão Geográfica e Geológica de São Paulo - ${ }^{3}$ quer realizando trabalhos de pesquisa de forma individual, ou atuando nas "casas de ciência" que por aqui existiam. Exemplo maior foi a presença constante de cientistas estrangeiros que fixaram residência no Brasil, como foi o caso do cientista suíço Emílio Goeldi, que colaborou de forma intensa na organização e ampliação das coleções do Museu Imperial, e, depois, foi trabalhar no Museu Paraense. ${ }^{4}$

Ressalta-se que o Museu Nacional foi uma instituição de pesquisa que realizou intensos intercâmbios com instituições similares da América Latina e da Europa. Por exemplo, sua revista - Archivos do Museu Nacional - deixa transparecer a contribuição de especialistas norte-americanos aos estudos taxonômicos e estratigráficos sobre as numerosas séries fósseis coletadas no início de 1870, nos trabalhos da Comissão Geológica do Império. Observamse também intercâmbios com instituições latino-americanas de coleções botânicas, zoológicas, mineralógicas e de informações sobre questões agrícolas. ${ }^{5}$

0 Brasil participou ativamente de várias exposições internacionais, primeiro somente na Europa, e depois inclusive nos Estados Unidos. Inicialmente reuniu seus produtos em algumas vitrines (Londres, 1851, 1862; Paris, 1855, 1867) e mais tarde construiu jardins e edifícios admiráveis (Paris, 1889; Chicago, 1893; Saint Louis, 1904; Nova lorque, 1939). As exposições internacionais constituíram-se em espaços de produção e reprodução de conhecimento por meio do imenso intercâmbio cultural e científico que se realizou entre os países. Elas tornaram possível trazer ao país as experiências de outras realidades socioeconômicas, ao mesmo tempo em que permitiu aos brasileiros levar suas próprias experiências. Elas foram lugares de ciências, local de encontros de cientistas e eventos paralelos como congressos científicos, de estabelecimentos de intercâmbios, de realização de trocas institucionais de produtos, entre outros aspectos. A internacionalização dos contatos entre diferentes regiões do mundo e a organização de um sistema de 
intercâmbio, impulsionada pelo liberalismo econômico, tiveram nas Exposições Universais seu motor, e a participação do Brasil nas mesmas foi um dos termômetros da internacionalização econômica e cultural do país. ${ }^{6}$

A participação do Brasil nas Exposições internacionais contou inclusive com o apoio do governo imperial. Para 0 Império, as exposições significaram uma oportunidade de apresentar aos olhos do mundo a sua natureza, as riquezas naturais que o país podia oferecer ao mercado, seja em forma de produtos alimentícios, os produtos agrícolas, seja em forma de matéria-prima para as indústrias, os produtos minerais. A participação do Brasil nas grandes exposições significou o coroamento do progresso do país que podia ser percebido no movimento de incentivo às ciências naturais para conhecer e explorar as riquezas naturais da terra. Nas vitrines dos eventos, o Brasil expunha o café, os feijões, 0 fumo, 0 açúcar e 0 algodão. Os especialistas em ciências naturais lá estavam participando diretamente do acontecimento, e em congressos que se realizavam em paralelo, divulgando os seus trabalhos científicos. ${ }^{7}$

Importante também foi a atuação dos norte-americanos na área médica, sobretudo os profissionais da Rockefeller Foundation. Esta assinou vários acordos de cooperação com o governo do Estado de São Paulo desde 1918. A instituição teve uma atuação fundamental nas atividades sanitárias, centradas nos primeiros postos de profilaxia que foram criados em áreas do interior do país, especialmente na região sul, e, na do ensino, com vistas à formação de profissionais do campo da saúde. A Faculdade de Medicina e Cirurgia e o Instituto de Higiene de São Paulo foram os maiores beneficiários dessa política. A partir da década de 1930, uma das prioridades da fundação foi a concessão de bolsas de estudos, para que latino-americanos fossem estudar nas universidades dos Estados Unidos nas áreas de ciências naturais. 0 Brasil foi um dos países que mais se beneficiou desse tipo de cooperação. ${ }^{8}$

Os pesquisadores brasileiros também participaram de diversos congressos científicos internacionais. Ganharam relevo os Congressos médicos latino-americanos ocorridos entre os anos de 1901 e 1922, e as Exposições Internacionais de Higiene, anexas aos Congressos. Estes eventos são representativos de um movimento mais amplo de intercâmbios científicos e organização do campo profissional da medicina na América Latina. Também foram de extrema importância para a circulação de ideias e de pessoas. ${ }^{9}$

Como argumentou Maria Amélia Mascarenhas Dantes, ${ }^{10}$ essas atividades, características de novos tipos de intercâmbios, ilustram a inserção dos cientistas brasileiros nos desdobramentos da profissão e na formação de comunidades científicas internacionais.

A implantação de universidades, como a Universidade de São Paulo, em 1934, e a Universidade Federal do Rio de Janeiro, em 1935, contribuíram para fortalecer os intercâmbios com a presença de pesquisadores em estadas de longa duração, desenvolvendo a pesquisa e o ensino. No caso da primeira, a maior parte do corpo docente da Faculdade de Filosofia, Ciências e Letras (FFCL), durante os seus primeiros anos de funcionamento, era constituída por professores estrangeiros. Físicos e matemáticos italianos, professores franceses em Ciências Sociais, todos tornaram-se sumidades em suas respectivas disciplinas, e contribuíram para dar uma imagem positiva à USP, como espaço de talentos, europeus e brasileiros. ${ }^{11}$

\section{A discussão e a criação de um conselho de pesquisas no Brasil}

Foi nas primeiras décadas do século XX que começou a despontar a ideia, ainda de forma bastante embrionária e incipiente, da criação de um conselho de pesquisas no Brasil.

As discussões sobre a criação de um conselho de pesquisas no Brasil ganharam destaque com a transformação da Sociedade Brasileira de Ciências na atual Academia Brasileira de Ciências (ABC), no ano de 1921, e a adesão desta instituição científica, no ano de 1923, ao International Research Council (IRC). A influência desta inserção reside na profunda impressão deixada pelos membros da $\mathrm{ABC}$ sobre a relevância do papel dos conselhos de pesquisa, já criados até então, no desenvolvimento científico de seus respectivos países. Nasceu, assim, a ideia de se começar a pensar 
na possibilidade de se criar um conselho de pesquisas no Brasil por acadêmicos como Álvaro Alberto da Motta e Silva e Miguel Osório de Almeida, cientistas que tinham participado de congressos do IRC. ${ }^{12}$

No ano de 1938, Carlos Chagas Filho, ao retornar da França, onde realizava um estágio, propôs a criação de um conselho de pesquisas no Brasil, semelhante ao que existia no território francês, o chamado CNRS. Encaminhou um projeto ao ministro Gustavo Capanema, que gostou bastante da ideia. Contudo, tal projeto acabou não sendo implantado. ${ }^{13}$

A ideia acima referida só ganharia vulto no final da década de 1940, mais precisamente, no chamado contexto do pós-guerra. Ao término da Segunda Guerra, o "status" da ciência perante a sociedade ascendera consideravelmente em função dos seus resultados, como a bomba atômica, o radar, a penicilina, mas também pela eficiência das suas formas de atuação bem simbolizada pela pesquisa operacional (PO), que aplicava durante o conflito a metodologia das ciências exatas e naturais no campo militar, e que, com o seu término, passou a ser estendida às atividades industriais. ${ }^{14}$

Momento ímpar para o processo de criação de um conselho de pesquisas ocorreu no ano de 1947, quando foram apresentados dois projetos de extrema relevância para o campo científico no Brasil. 0 primeiro foi o do Instituto Internacional da Hileia Amazônica (IIHA), apresentado por Paulo Carneiro, em maio, numa reunião do Instituto Brasileiro de Educação, Ciência e Cultura (IBECC), órgão do Ministério das Relações Exteriores, que fazia relação com a Unesco. ${ }^{15}$ Este projeto já havia sido apresentado pela delegação brasileira que esteve, em novembro de 1946, na primeira Reunião Geral da Unesco, realizada em Paris. A delegação do Brasil era composta pelos cientistas Carlos Chagas Filho e Olympio da Fonseca, e 0 embaixador do Brasil em Londres, Moniz de Aragão. Este projeto foi considerado prioritário pela Unesco. ${ }^{16}$

0 segundo foi a instalação de uma subcomissão para a organização da pesquisa científica no Brasil no âmbito do IBECC, ocorrida também em maio do mesmo ano. Esta comissão era composta por dois cientistas que integraram a delegação do Brasil na Unesco, além de Cristóvão Leite de Castro, Arthur Ramos e Lélio Gama. No ano seguinte, Carlos Chagas Filho apresentou um plano de organização do Conselho Nacional de Pesquisas, noutra reunião do IBECC, como fruto dos trabalhos daquela subcomissão. Dessa forma, o que se observa é que a discussão para a organização e financiamento da pesquisa científica no país estava acontecendo no meio científico. ${ }^{17}$

Álvaro Alberto da Costa e Silva, ${ }^{18}$ no ano de 1946, quando foi criada a Comissão de Energia Atômica na Organização das Nações Unidas (CEA/ONU), e o Brasil recebeu o convite para ser um dos países-membros, foi nomeado representante brasileiro e participou das discussões sobre a questão da energia nuclear naquela Comissão. 0 Brasil era um país produtor de matéria-prima para a energia nuclear e, portanto, deveria possuir assento naquele espaço. Álvaro Alberto nas reuniões defendeu a tese de compensações específicas, criticando arduamente a posição de expropriação pura e simples das matérias-primas pelos países que detinham a tecnologia de produção dos minerais atômicos. ${ }^{19}$

\section{A criação do CNPq no movimento de internacionalização das ciências do pós-guerra}

A criação da Unesco, integrante da ONU, em novembro de 1945, foi um marco na medida em que preconizou um plano de reconstrução das relações científicas internacionais. Nesse projeto, a ciência era vista como internacional, universal e neutra, possibilitando as trocas entre as diversas sociedades e 0 enriquecimento cultural e científico comum. A cooperação científica internacional permitiria, acima de tudo, a emergência de valores comuns a todos os países. Cooperação, inter-relações, diversidade de valores, comunicação foram os princípios que embasaram as ações da Unesco no seu momento inicial, e estiveram presentes nas ações do seu primeiro diretor-geral, Julian Huxley. ${ }^{20}$

0 projeto de uma nova organização social da ciência estava, por isso, sendo gestada no âmbito daquela agência internacional. Joseph Needham, primeiro diretor da Seção de Ciências Naturais da organização, foi quem melhor a traduziu em seu periphery principle. 0 bioquímico propôs um programa visando à aplicação científica em países que, embora não atingidos diretamente pela guerra, poderiam "desenvolver" os conhecimentos e, consequentemente, eles próprios. No ambiente deste 
programa, a ciência era vista como internacional e neutra, possibilitando as trocas entre as diversas sociedades e a emergência de valores comuns a todos os países. ${ }^{21} \mathrm{E}$, para muitos cientistas, a cooperação internacional representava um meio de não só continuar o seu compromisso antifascista, porém também a prevenção do uso destrutivo da ciência na era pós-guerra.22

Needham partilhava uma visão na qual deveria ser construída uma rede voltada para a ação reunindo "cientistas missionários sem vínculos". No plano da Unesco, o cientista teve oportunidade de tentar traduzir em realidade essa visão, de utilizar a presença ativa da organização em diferentes partes do mundo para ampliar o escopo do princípio universalista que formava o cerne do internacionalismo científico. Ele estimulou o surgimento de escritórios de intercâmbio científico e técnico nas principais capitais do mundo, escritório estes que teriam recursos financeiros, secretarias e equipamentos adequados. Além disso, não estariam confinados a uma única ciência, tendo aprovação para realizar tudo aquilo que fosse necessário para apoiar uma cooperação científica melhor entre os países por eles conectados. ${ }^{23}$

Consoante expôs Marcos Chor Maio, ${ }^{24}$ para os cientistas-intelectuais Julian Huxley ou Joseph Needham, a ciência não deveria ser controlada pelos Estados-membros. 0 desenvolvimento e a difusão do conhecimento científico não estariam limitados às fronteiras nacionais. Tratava-se de um empreendimento transnacional. Para estes homens que estavam empenhados na construção da Unesco, a ciência seria mais eficaz uma vez que suas atividades estivessem sob o controle dos próprios cientistas. 0 programa da Divisão de Ciências Naturais, aprovado na $1^{\text {a }}$ Sessão da Conferência Geral da Unesco, em novembro de 1946, confirmava o princípio da não intervenção estatal.

Formou-se, então, redes de cooperação com a instalação de escritórios regionais da Unesco de Ciência e Tecnologia em diversos países, como o Cairo (1947), Nova Déli (1948), Montevidéu (1949), Jacarta (1951) e Nairobi (1965). Inicialmente, eles foram chamados de Escritórios de Cooperação Científica. No entanto, coerentemente com o ideal de Needham, influenciado pelo marxismo, de uma ciência socialmente responsável, o bioquímico havia proposto um Serviço Mundial de Cooperação Científica. ${ }^{25}$ No pós-guerra, a ciência deveria ser convocada para a luta contra a ignorância, a pobreza e a doença. Ela deveria assumir imediatamente uma função de esclarecimento e de promoção do bem-estar. E, para a concretização desse ideal, urgia a criação de instituições internacionais de pesquisa, ideia defendida por Levy Hyman e Henri Laugier e apoiada por Neddham e outros cientistas da Unesco, localizadas em muitos países e abertas a pesquisadores de todas as nacionalidades. ${ }^{26}$

Nestes novos tempos de paz, os cientistas assumiram funções cruciais com base na cooperação científica internacional. E no Brasil impelia a necessidade de criação de um conselho de pesquisas para promover e estimular o desenvolvimento da investigação científica e tecnológica nos distintos ramos do conhecimento. Foi, logo, neste contexto do pós-guerra que se observou um esforço de união dos cientistas em prol de um conselho de pesquisas no universo brasileiro.

Nesse momento, a energia nuclear tornou-se um indicador preciso do "status" da ciência. A geração de conhecimento científico voltada para a produção da energia nuclear estava no âmago de propostas que buscavam novas bases de desenvolvimento da ciência em nossa sociedade. Assim, no início dos anos de 1950, no século XX, ciência, tecnologia e energia nuclear estavam estreitamente vinculados. A ciência era vista como fator de desenvolvimento econômico e segurança nacional com 0 emprego da energia nuclear. ${ }^{27}$

Foi nessa circunstância que ganhou destaque a atitude de Álvaro Alberto na Comissão de Segurança da ONU, em prol da participação do Brasil na pesquisa científica de energia nuclear. E, conforme bem salientou Heloísa Domíngues, ${ }^{28}$ o Brasil, como detentor de grandes jazidas dos minerais atômicos, era visto como um espaço geográfico a ser explorado cientificamente. Tal fato fez com que a representação brasileira, por intermédio de Álvaro Alberto, se movimentasse no sentido de integrar o programa nuclear internacional não apenas como um espaço geográfico, mas também com a participação ativa de seus cientistas nas pesquisas. ${ }^{29} \mathrm{E}$, foi exatamente nesse contexto que se deu o estímulo social à criação de um conselho de pesquisas no Brasil, nascido com base nos debates que se travaram na Comissão de Energia Nuclear (CEA) da ONU, em torno do estabelecimento de uma política internacional de energia nuclear. ${ }^{30}$

No cenário dos anos de 1950, no segundo governo Vargas, momento de intensas manifestações nacionalistas na sociedade brasileira, e que já vinham ocorrendo desde o final da segunda Guerra, a C\&T tinha lugar no quadro na- 
cional, principalmente graças à industrialização em curso, que estava sendo impulsionada pelas ações decorrentes da Assessoria Econômica daquele governo, chefiada por Rômulo de Almeida. Tais ações viabilizaram a Petrobras, o Fundo Nacional de Eletrificação, o Plano Nacional do Carvão, a Capes, a Comissão de Desenvolvimento Industrial, o Plano Nacional de Babaçu, a Subcomissão de Tratores, Jeeps, Caminhões e Automóveis e o CNPq. A tecnologia e a ciência estavam, por conseguinte, imiscuídas na vida cotidiana e no imaginário dos brasileiros. ${ }^{31}$

Fruto de uma discussão gestada no meio científico, a criação do CNPq (Lei n. 1.310/1951) e a sua efetiva concretização e organização se deram no âmbito de uma rede de cientistas que se ligaram à ONU e à Unesco, então lugares de encontros e de trocas científicas de todos os países preocupados com a organização cultural e científica. ${ }^{32}$

Acrescenta-se que a esse grupo aliaram-se empresários, políticos, militares e outros cientistas, todos empenhados no projeto de desenvolvimento da pesquisa científica no Brasil. Os ideais políticos desse grupo eram, respectivamente, fazer ciência para melhorar o Brasil e garantir a segurança nacional..$^{33} 0$ primeiro presidente do Conselho, como já dito anteriormente, foi Álvaro Alberto, cientista-militar que inegavelmente lutara pela sua concretização.

\section{Os institutos de pesquisa criados pelo CNPq na Gestão Álvaro Alberto e engajados no projeto de internacionalização das ciências}

Na gestão Álvaro Alberto foram criados três instituições: 0 Instituto Nacional de Pesquisas da Amazônia (INPA), o Instituto de Matemática Pura e Aplicada (IMPA) e o Instituto Brasileiro de Bibliografia e Documentação (IBBD). Esses três institutos de pesquisa foram criados no âmbito do movimento de internacionalização das ciências no pós-guerra, no qual o CNPq estava inserido, e estavam de acordo com uma das linhas de ação da Unesco de:

(...) manter, aumentar e difundir o conhecimento por meio de diversas ações, como promover o intercâmbio de pesquisadores e de publicações, auxiliar na manutenção de monumentos históricos e acervos bibliográficos como parte da cultura de cada nação, conceder apoio financeiro para as associações científicas e aos pesquisadores, criar novas formas de cooperação científica internacional, como laboratórios e institutos científicos, dentre outras iniciativas. ${ }^{34}$

0 INPA foi criado pelo Decreto n. 31.672, de 29 de outubro de 1952, com sede em Manaus, e se espelhou, em grande parte, na proposta do IIHA, projeto, que como já argumentamos, foi considerado um dos quatro principais no âmbito da Unesco no ano de 1947, mas não conseguiu ser implementado. Muitos dos personagens envolvidos com a tentativa de criação do IIHA estariam também empenhados no projeto do INPA: Paulo Carneiro, Heloísa Alberto Torres, Felisberto Camargo, Carlos Chagas Filho, Olympio da Fonseca, entre outros. ${ }^{35}$ Ademais, o projeto do INPA insistia na ideia de uma ciência para a Amazônia inserida no campo da produção científica internacional, objetivo este também presente no IIHA. Como enfatizaram Heloísa Domingues e Patrick Petitjean, o INPA significou uma nacionalização do projeto científico do IIHA, todavia não uma oposição. ${ }^{36}$

Por sua vez, o IBBD (atual IBICT) foi criado pelo Decreto n. 35.124, de 27 de fevereiro de 1954, mediante proposta conjunta do CNPq e da Fundação Getúlio Vargas, e seguia as diretrizes da Unesco de investir na criação de centros bibliográficos nacionais. Uma das suas finalidades era promover o intercâmbio de documentação e de informação entre instituições nacionais e entre estas e instituições estrangeiras ou internacionais.

A Unesco considerava de extrema relevância os serviços bibliográficos nacionais. Estes eram vistos como um meio de aumentar a eficiência e a economia dos estudos, e de intensificar a atividade em todos os campos da educação, da ciência e da cultura. De acordo com a organização, o planejamento sistemático desses serviços guarda estreitas relações com a prosperidade econômica e científica de um país, e os lugares onde estão mais desenvolvidos são aqueles que mais se preocupam com o desenvolvimento desses centros bibliográficos para a vida nacional. Assim, segundo a organização, 
É um feito significativo que na Unesco não exista nenhuma seção nem nenhum serviço que não tenha que se preocupar, de uma maneira ou de outra, com o desenvolvimento da bibliografia e que sejam numerosos os comitês criados para resolver os problemas de ordem bibliográfico que se apresentam em determinados ramos da investigação. (...) a criação de certos serviços fundamentais contribuem para a coordenação de atividades mais especializadas, a favorecer a economia e a auxiliar uma ajuda prática na intercomunicação bibliográfica tanto nacional como internacional. ${ }^{37}$

No ano de 1950 foi realizada uma conferência internacional na própria Unesco que teve como fim o aperfeiçoamento da bibliografia. Nesse evento se discutiu a importância da atuação da organização para estimular a criação de centros bibliográficos e a confecção de bibliografias nacionais, igualmente se criou um Comitê Consultivo Internacional Permanente de Bibliografia. Levando em consideração as decisões tomadas na referida conferência, a Unesco passou a estimular e a sugerir a criação de serviços bibliográficos em diversos países, e a elaborar manuais bibliográficos que tratassem de diferentes aspectos da bibliografia nacional e internacional. Essas ideias estavam no âmago das propostas defendidas por Pierre Auger, físico francês, que substituiu Needham no âmbito da Seção de Ciências Naturais da organização, e que defendia uma visão da ciência em que enfatizava o intercâmbio de informação, a ajuda e a reconstrução no pós-guerra. A informação era necessária para quebrar o isolamento entre os cientistas, agravado pela guerra, e era parte essencial da maquinaria de assessoramento científico que estava sendo construída gradualmente pelos governos no período do pós-guerra. ${ }^{38}$

A criação do IBBD insere-se no plano dessa política internacional de criação de centros bibliográficos nacionais apoiados pela Unesco, cuja principal função ia de encontro aos ditames estabelecidos pela organização, que distribuiu bolsas de estudos para estrangeiros irem elaborar e divulgar informações bibliográficas.

Por seu turno, o Instituto de Matemática Pura e Aplicada foi criado pela Portaria n. 42-A do Presidente do CNPq, em 15 de outubro de 1952, tendo sua existência sido homologada pelo Decreto n. 39.687, de 07 de agosto de 1956. Consoante o seu Regimento, o IMPA tinha por finalidade desenvolver as atividades de ensino e de investigação científica no campo da Matemática pura e aplicada, assim como a difusão e o aprimoramento da cultura matemática no país.

Convém registrar que, na sequência da devastação provocada pela Segunda Grande Guerra, a comunidade científica internacional estava ansiosa para reviver o espírito de cooperação científica. No ano de 1951 foi restabelecida a International Mathematical Union (IMU) e foi organizado um comitê interino para conduzir as negociações necessárias, com a participação de diversos países, para a realização do Primeiro Congresso Geral da IMU, no ano de 1952. Nesse último ano, o IMU foi admitido no International Council of Scientific Unions (ICSU) e tornou-se o maior parceiro da Unesco. Como a única agência das Nações Unidas preocupada com a disciplina, a Unesco veio a desempenhar um papel crítico internacional no campo da Matemática. ${ }^{39}$

Desde a sua criação, a Unesco realizou importantes iniciativas no campo das ciências matemáticas, visando sempre estimular a cooperação científica internacional na área. Reconhecendo a qualidade da formação e do treinamento de bons matemáticos para o desenvolvimento do mundo, a instituição via com bons olhos a criação de órgãos preocupados com o ensino e a pesquisa da Matemática. E o Brasil seguiria essa tendência ao criar o IMPA, instituição científica dedicada às ciências matemáticas. 0 intenso intercâmbio de pesquisadores nacionais e estrangeiros foi uma marca da referida instituição, reforçando o espírito da cooperação científica internacional conforme preconizada pela Unesco.

\section{A política de bolsas e auxílios do CNPq nos anos 1951 a 1955}

A criação do CNPq contribuiu para atenuar as limitações impostas pela origem social à partida para o exterior, no instante em que buscou criar uma política sistemática de formação intelectual nos grandes laboratórios reconhecidos internacionalmente. Com esse apoio, um grande número de universitários brasileiros teve acesso a universidades e 
instituições de pesquisa em diversas regiões do mundo e, assim, obteve títulos. Aliás, o alcance das ações de capacitação foi estendido a todas as áreas, não se restringindo às ciências exatas e biomédicas. ${ }^{40}$

A análise do período de 1951 a 1955 é bastante profícua, pois nos permite observar como essa agência governamental iniciou a sua política de financiamento e concessão a bolsas de estudo e pesquisa, e auxílios, permitindo que pesquisadores brasileiros se doutorassem no exterior. Assim, faz-se uma análise primeira de bolsas concedidas a pesquisadores brasileiros e auxílios para o exterior, do mesmo modo que a cientistas estrangeiros que para cá vieram realizar pesquisas em nossas instituições, ou formar pesquisadores, ou proferir palestras. 0 que nos interessa é a circulação internacional dos cientistas e a sua formação em última instância para o desenvolvimento da ciência e da tecnologia no Brasil.

Criado o Conselho, fazia-se necessário redigir as instruções para a concessão de auxílios e bolsas. Estas foram aprovadas na Sessão do Conselho Deliberativo do CNPq, de 12 de julho de 1951. Os auxílios foram classificados em: auxílios para realização da pesquisa; para melhoramento das condições gerais de pesquisas (aparelhamento de laboratórios, bibliotecas, entre outros); e para formação ou aperfeiçoamento dos pesquisadores (concessão de bolsas de estudo, organização de cursos, seminários, entre outros). Quanto às bolsas, havia duas modalidades: a de estudo e a de pesquisa. Esses mecanismos de concessão de bolsas e auxílios vigoraram durante todo o período da gestão Álvaro Alberto. ${ }^{41}$

Essas regras para a distribuição de bolsas e auxílios foram mantidas até setembro de 1955. Antes disso, em março, Álvaro Alberto deixara a presidência, ${ }^{42}$ em meio a uma crise política no CNPq, em que surgiram fortes acusações de corrupção a ele no âmbito do programa nuclear brasileiro, especificamente quanto ao projeto dos sincrocíclotrons. Mesmo assim, o cientista-militar conseguiu aprovar no Conselho Deliberativo a criação da Comissão de Energia Atômica (CEA), em janeiro de 1955, instância consultiva do CNPq, salvando assim as diretrizes da política nacional de energia nuclear aprovadas por Getúlio Vargas e pelo Conselho de Segurança Nacional, em 1953. A CEA teve uma vida curta, sendo extinta e substituída pela Comissão Nacional de Energia Nuclear (CNEN), criada em outubro de 1956. ${ }^{43}$

0 esvaziamento da pesquisa em energia nuclear, no âmbito do Conselho, provocaria mudanças na estrutura interna relativas à prática de distribuição de bolsas. Concorreu ainda para esta mudança, na concepção de Ana Maria R. de Andrade, ${ }^{44}$ os graves problemas ocorridos na esfera econômica ocasionados pela brusca elevação da taxa de inflação, que acabaram por ocasionar o atraso na liberação das verbas por parte do governo federal e por provocar oscilações nos valores dos orçamentos anuais do CNPq. Em consequência, tornou-se necessária a reformulação da política do órgão quanto à distribuição de bolsas e auxílios. Assim, foram elaboradas as Novas Instruções para a Concessão de Bolsas e Auxílios (outubro de 1955). ${ }^{45}$

A análise das $A_{t a s}{ }^{46}$ e dos Anais referentes às Sessões de Reuniões do Conselho Deliberativo (CD) do CNPq, no período já mencionado, nos permite observar que diversos brasileiros conseguiram auxílios e bolsas de estudo para ir estudar no exterior, e, dessa maneira, realizar o seu doutoramento; fazer viagens de pesquisas para acompanhar investigações em laboratórios no estrangeiro; estágios em renomados centros científicos europeus e dos EUA; auxílios para participar de congressos e reuniões científicas internacionais, entre outros. Por outro lado, inúmeros professores e pesquisadores estrangeiros vieram ao Brasil realizar pesquisas, proferir palestras e oferecer cursos nas universidades nacionais. Esses fatos deixam transparecer que, nos seus primeiros anos, o órgão investiu nos intercâmbios e trocas científicas e na circulação internacional de cientistas, com a concessão de auxílios e bolsas de diferentes tipos. ${ }^{47}$

Salienta-se que a leitura das Atas e Anais do CD do CNPq deixa transparecer a onipresença absoluta do presidente nessas reuniões. Ele deu o tom em todas elas, comandando-as firmemente e desempenhando um papel de liderança inquestionável, nomeando os "fiéis" conselheiros e determinando as decisões conclusivas. ${ }^{48} \mathrm{~A}$ palavra final era sempre aquela por ele emitida. Havia as comissões do Conselho Deliberativo e as divisões técnico-científicas que analisavam os pedidos de bolsas e auxílios. Os conselheiros elaboravam os pareceres, que eram apresentados nas reuniões do CD. A aprovação final dependia do crivo do presidente do CNPq. Álvaro Alberto era o líder, que deferia ou não as concessões de bolsas e auxílios, detendo, portanto, o controle das decisões. No período de 1951 a março de 1956, o CNPq se confundia com a pessoa do seu presidente. A política de distribuição de bolsa e auxílios, seja para o Brasil ou para 0 exterior, deveria atender aos seus interesses e objetivos. 
0 CNPq, ainda no âmbito de sua política de cooperação científica internacional, financiou a filiação do Brasil ao ICSU; à União Internacional de Física Pura e Aplicada; ao Bureau International des Poids et Mesures; adesão do Brasil à Union Internationale de Mécanique, por meio de solicitação do Instituto Nacional de Tecnologia; adesão do Brasil à União Matemática Internacional; intercâmbio com o Batelle Memorial Institute e instalação no Brasil de um laboratório para estudar problemas técnico-industriais. Ainda na gestão de Álvaro Alberto, iniciaram-se os contatos para a celebração do contrato de convênio entre o Conselho Nacional de Pesquisas do Brasil e o Consiglio Nazionale Delle Richerche da Itália, para o intercâmbio de cientistas, acordo assinado em 15/06/1955, já na gestão de José Baptista Pereira.

Registra-se também que o CNPq, ainda no espírito da cooperação científica internacional, foi o responsável pelo financiamento das diárias dos primeiros pesquisadores visitantes estrangeiros selecionados pela Unesco para atuar no CBPF, como Giuseppe Occhialini, Gerard Hepp, Helmut Schwartz, Gert Moliére, entre outros. 0 auxílio concedido pelo Conselho fazia "parte da política de intercâmbio cultural e científico do Conselho" ${ }^{49}$

Nesses primeiros anos do CNPq, a questão em torno da energia nuclear foi tema central na política de fomento do órgão. Conforme mostrou Ana Maria R. de Andrade,50 as ciências nucleares foram as que receberam maior volume de recursos, e o Centro Brasileiro de Pesquisas Física o órgão que obteve inúmeros privilégios, o maior volume de recursos do Setor de Física, e o polêmico projeto de montagem e construção dos sincrocíclotrons. Dentre os apoios concedidos pelo órgão para este assunto, no tocante à circulação e cooperação científica internacional, estão:

- a missão estrangeira que veio ao Brasil, no ano de 1951, chefiada pelo sr. Gordon Dean, da United States Atomic Energy Comission, para tratar da exportação de minerais radioativos;

- a viagem de Álvaro Alberto aos EUA e Canadá, entre 1951 e 1952, quando retomou o contato com o presidente da AEC, e encontrou professores das universidades de Chicago e Colúmbia;

- a organização do Simpósio sobre Novas Técnicas de Pesquisa em Física, promovido no ano de 1952, pela Academia Brasileira de Ciências, com a colaboração do Centro de Cooperação Científica da América Latina, representação da Unesco sediada em Montevidéu. Financiados pelo CNPq, vieram para o Brasil muitos físicos estrangeiros, como Isidor I. Rabi (Universidade de Colúmbia, Prêmio Nobel de Física, Consultor da Comissão de Energia Atômica dos EUA), Eugene Wigner, Emilio Segré, David Bohm, Sergio de Benedetti, Martin Deutsch, R. G. Herb, Ricardo Gans, Manuel Sandoval Vallarta, Marcos Moshinsky, Fernando de Alba, José Balseiro, Phillip Smith, Herbert Anderson, John Marshall, Leona Marshall, entre outros;

- a participação de pesquisadores brasileiros na Conferência de Física Nuclear (Glasgow, 1954);

- a visita do general Leslie Groves, da Comissão de Energia Atômica dos EUA, ao CNPq, no ano de 1955;

- 0 acordo entre o Brasil e os EUA, firmado em 1955, no qual se previu a cessão de Urânio 235 para um reator experimental, e a colaboração americana em um programa de prospecção do solo brasileiro, visando ao descobrimento de novas ocorrências de materiais radioativos;

- o Conselho financiou, no ano de 1955, a delegação brasileira na Conferência Internacional de Energia Atômica para Fins Pacíficos, realizada em Genebra. A delegação brasileira foi presidida pelo General Bernardino Corrêa de Mattos Netto, e da qual participaram também os professores Elysiário Távora, Ernani da Motta Rezende, Joaquim da Costa Ribeiro, José Leite Lopes e Marcelo Damy de Souza Santos;

- ainda no ano de 1955, ocorreu a visita do presidente do CNPq, José Baptista Pereira, do presidente da Comissão de Energia Atômica do CNPq, General Bernardino de Mattos, e do professor José Goldemberg à Usina Atômica de Chalk River, a convite da Comissão de Energia Atômica do Canadá.

Diversos estudantes brasileiros foram contemplados com bolsas para ir estudar no estrangeiro. Dentre os países que mais receberam bolsistas brasileiros para a realização de estudos e pesquisas, no período de 1951 a 1955, aparecem: 


\begin{tabular}{ll}
\hline RELAÇÃO DE PAÍSES & NÚMERO DE BOLSISTAS \\
\hline EUA & 155 \\
\hline França & 28 \\
\hline Europa $^{51}$ & 10 \\
\hline Inglaterra & 08 \\
\hline Alemanha & 06 \\
\hline Canadá & 05 \\
\hline Suécia & 04 \\
\hline Suíça & 02 \\
\hline Chile & 02 \\
\hline Itália & 02 \\
\hline África & 01 \\
\hline México & 01 \\
\hline
\end{tabular}

Do quadro ao lado observa-se que os cientistas brasileiros canalizaram, naquele momento, 0 intercâmbio científico para os EUA. A análise da documentação também informa que a maioria desses bolsistas era da área médica, que iam realizar o seu doutorado ou cursos de especialização no exterior. Assim, há que se sublinhar que apesar de as ciências nucleares serem aquelas de maior interesse para aqueles que estavam à frente do CNPq, as ciências biológicas, nos cinco primeiros anos de atividades do Conselho, foram as que mais receberam recursos da Divisão Técnico-Científica para bolsas e auxílios, superando as ciências físicas. ${ }^{52}$

Nos anos de 1952 a 1955, 41\% das bolsas de pesquisa no exterior foram para as ciências biológicas, com a finalidade de especializar médicos. Carlos Chagas Filho, diretor da Divisão de Pesquisas Biológicas, informou numa das reuniões do Conselho Deliberativo que "80\% (oitenta) dos bolsistas que foram aos EUA e a Europa eram médicos, e desses bolsistas certamente $50 \%$ foram com programa médico bem caracterizado".53 Essa afirmação de Carlos Chagas foi reiterada por Antonio Couceiro, que informou ao Conselho Deliberativo que, após uma análise da relação de bolsas concedidas no estrangeiro no período de 1952 a 1955, apenas 14 bolsas foram disponibilizadas para 0 setor de pesquisas agronômicas, enquanto 0 Setor de Pesquisas Biológicas recebeu 91, e, "verifica-se que dessas 91 bolsas, 58 foram concedidas a médicos, para fazerem cursos de especialização em medicina pura e simplesmente, e 14 outras foram concedidas a médicos" . ${ }^{4}$

Na 319a Sessão do Conselho Deliberativo do CNPq, de 26 de abril de 1956, o conselheiro Olympio da Fonseca apresentou a proposta de criação e organização de um setor de pesquisas médicas, em função do elevado número de bolsas e auxílios que estava sendo concedido ao referido setor.

0 primeiro conselheiro a pedir a palavra foi Carlos Chagas Filho, diretor do Setor de Pesquisas Biológicas. 0 renomado biofísico informou que o estava acontecendo era "uma verdadeira avalanche de pedidos médicos, os quais nós nem sempre podemos atender" ${ }^{55} \mathrm{~A}$ seguir, informou sobre 0 elevado número de bolsistas brasileiros que foram para o exterior e, destes, como já mencionado no parágrafo acima, "80\% são médicos". Na percepção do conselheiro, "onde os nossos bolsistas fracassaram foi exclusivamente no setor médico" e, segundo ele, este fracasso se devia "à formação médica fornecida pela Faculdade de Medicina". ${ }^{56}$ E apresentou a razão para tal fato:

A percentagem do não aproveitamento no setor médico é maior do que nos outros setores. Tivemos tal pressão exercida sobre o Conselho para o envio de bolsistas médicos profissionais que não poderíamos, na verdade, quando atuamos muitas vezes forçados por contingências que escapam ao rigor técnico, deixar de prever e observar mais tarde um resultado menos justo, menos desejável do que nos outros setores. ${ }^{57}$

Esses "bolsistas médicos profissionais", ao retornar do estrangeiro após concluir seus cursos de doutorado, voltavam para atuar nos seus consultórios particulares, e não nas instituições públicas de pesquisa e ensino. Seguindo as próprias palavras de Carlos Chagas, "na prática médica nós verificamos que todo mundo receita"58, deixando assim transparecer a tradição médica de se dedicar às atividades clínicas, à prática do dia a dia nos consultórios.

No que lhe diz respeito, o conselheiro Olympio da Fonseca justificou a razão para se criar um setor médico, separado do setor de Biologia, para que se desse o mesmo valor tanto para os projetos de pesquisas médicas de ordem clínica como para aqueles que fossem voltados para investigações exclusivamente de laboratório. Sob a ótica do conselheiro, não deveria haver oposição a auxílio para pesquisas clínicas, e caso existisse, tal fato ocorria em função da "tendência natural do espírito do homem que faz investigações exclusivamente de laboratório" ${ }^{59} \mathrm{Em}$ oposição, Carlos Chagas respondeu que sua atuação à frente do Setor foi sempre a de prestigiar a pesquisa médica e a clínica, 
(...) desde que estivessem bem credenciadas. Todas as vezes que encontrei um programa de pesquisa médica de importância, ou que me pareceu de importância, e todas as vezes que se me deparou um bom candidato procurei auxiliá-lo de todos os modos. Nunca houve ideia preconcebida. ${ }^{60}$

Outrossim, Olympio da Fonseca justificava a sua proposta pelo fato de o "setor de Biologia ter naturalmente um interesse essencialmente biológico e não médico. Ao setor médico é que caberia atender a essa outra ordem de assuntos que só de longe interessam ao biologista". ${ }^{61}$

Ao final da sessão foi constituída uma comissão para que fosse avaliada a proposta apresentada. Essa comissão seria constituída pelos seguintes membros: Arthur Moses, Olympio da Fonseca, Magalhães Gomes e pelo Diretor da Divisão Técnico-científica.

Dos cientistas que receberam bolsas e auxílios no período de 1951 a 1956, de um total de 1.140, 20\% ganhou financiamento para completar a sua formação e desenvolver projetos de pesquisa no exterior (228). Desse percentual, $25 \%$ foram os que tiveram maior número de projetos no período (49, aparecem com número de frequência de deferimento de 4 a 7 projetos para o exterior).

Com relação às áreas do conhecimento, neste "seleto" grupo de pesquisadores, os cientistas que mais foram contemplados são aqueles das Ciências Biológicas / História Natural, conforme se constata no quadro abaixo:

\begin{tabular}{ll}
\hline ÁREA DO CONHECIMENTO & NÚMERO DE CIENTISTAS \\
\hline Ciênnias Biológicas / História Natural & 17 \\
\hline Ciências Biológicas / Medicina & 12 \\
\hline Ciências Físicas & 08 \\
\hline Ciênnias Geológicas & 06 \\
\hline Ciências Matemáticas & 04 \\
\hline Ciências Químicas & 02 \\
\hline
\end{tabular}

Convém registrar que a formação em História Natural ainda existia nesse momento. Muitos pesquisadores se formaram em História natural, na Faculdade Nacional de Filosofia da Universidade do Brasil (FNFi/UB) e da Universidade de São Paulo - faculdades que tiveram papel fundamental na formação de profissionais com carreiras em instituições de pesquisa do Rio de Janeiro e São Paulo. No curso de História natural havia as disciplinas básicas de Botânica geral, Geologia, Zoologia, Mineralogia, Citologia, Paleontologia, Anatomia, Histologia, Taxonomia, Fisiologia, Ecologia e Genética. Tanto que os pesquisadores do Museu Nacional do Rio de Janeiro eram chamados de naturalistas. Este termo aos poucos, mormente nos anos 1950, foi sendo substituído por "Biologia experimental" ou apenas "Biologia", que engloba 0 ideal de uma disciplina geral, universal. ${ }^{62}$

No cenário nacional, esse quadro foi modificado na segunda metade da década de 1960, quando se consolidou e foi executado o projeto de reforma da universidade brasileira. 0 Decreto-lei n. 53, de 18 de novembro de 1966, introduziu princípios e normas para as Universidades Federais, e no Decreto-lei n. 252, de 28 de fevereiro de 1967, foram estabelecidas normas complementares ao Decreto-lei n. 53/1966. Uma das consequências foi o desmembramento dos cursos das faculdades de Filosofia, Ciências e Letras, que passariam às unidades (institutos, escolas, faculdades) recém-criadas, consoante preconizava 0 artigo $2^{\circ}$, I, do Decreto-lei de $1966 .{ }^{63}$

Como salientou Afrânio Garcia Jr. ${ }^{64}$ a concessão de bolsas aos candidatos a estudos internacionais por parte das agências de fomento, salientando aqui o caso do CNPq, alterou profundamente as chances de viajar ao exterior, diminuindo o peso da seleção baseada apenas no patrimônio econômico da família de origem ou em capital social e político que a ele se associava. Assim, com a criação do CNPq aumentaram as chances dos que haviam investido em percursos escolares de alto rendimento e que acreditavam em justificativas da meritocracia, dispondo que os cargos da 
alta administração pública ou privada deveriam ser providos pelos que mais dispunham de diplomas e competências, os "mais capazes".

Ademais, ainda seguindo o autor supracitado, o estudo do caso brasileiro chama a atenção para a importância assumida pelo financiamento da formação internacional de novas gerações de dirigentes pelo Estado, ou melhor, como a aquisição de diplomas e competências em instituições de prestígio internacional por jovens brasileiros foi transformada em "questão de Estado", podendo justificar um investimento de recursos do Tesouro Nacional. ${ }^{65}$

Retornando à análise do estudo, informa-se que foi intensa a presença de cientistas estrangeiros no período supracitado, todos financiados pelo CNPq, seja para proferir palestras, realizar atividades de pesquisa e ensino, visitar instituições, participar de congressos científicos, entre outras atividades. ${ }^{66}$

Diversos cientistas brasileiros foram contemplados com auxílios do CNPq para participar de congressos internacionais, ${ }^{67}$ visitar diversas instituições de pesquisa e ensino ${ }^{68}$ realizar viagens de estudos ${ }^{69}$ proferir palestras, ${ }^{70}$ representar o conselho em eventos científicos internacionais, ${ }^{71}$ assim como se observa 0 auxílio do Conselho para a aquisição e permutas de revistas e aquisição de obras científicas estrangeiras por instituições brasileiras, ${ }^{72}$ aparelhagem para laboratórios ${ }^{73}$ que representa mais uma forma de circulação dos conhecimentos científicos.

Em relação às viagens financiadas pelo Conselho para congressos, visita a laboratórios, instituições de ensino e pesquisa, os países de destino para onde os cientistas brasileiros foram se apresentam como sendo os seguintes:

\begin{tabular}{ll} 
PAÍSES & NÚMERO DE \\
& $\begin{array}{l}\text { CIENTISTAS } \\
\text { BRASILEIROS }\end{array}$ \\
\hline EUA & 52 \\
\hline França & 14 \\
\hline Argélia & 10 \\
\hline Mexico & 08 \\
\hline Inglaterra & 05 \\
\hline Alemanha & 04 \\
\hline Canadá & 02 \\
\hline Chile & 02 \\
\hline Espanha & 02 \\
\hline Uruguai & 02 \\
\hline Portugal & 02 \\
\hline Itália & 02 \\
\hline Japão & 01 \\
\hline Colômbia & 01 \\
\hline Porto Rico & 01 \\
\hline Bélgica & 01 \\
\hline Suécia & 01 \\
\hline Suíça & 01 \\
\hline Bolívia & 01 \\
\hline Guatemala & 01 \\
\hline Israel & 01 \\
\hline & \\
\hline
\end{tabular}

Do quadro ao lado observa-se que os EUA e a França foram os lugares mais procurados pelos pesquisadores brasileiros, sobretudo pela posição de destaque que estes dois países ocupavam no cenário científico internacional. Todavia, a surpresa ficou por conta da presença da Argélia ocupando a terceira posição. Ocorre que, no ano de 1952, o Conselho financiou a ida de um grupo de geólogos (dentre os quais estavam Luciano Jacques de Morais, Wilhelm Kegel, Fernando Flávio Marques de Almeida, Lewellyn Ivor Price, Geraldo Conrado Malcher, Otávio Barbosa, Victor Leinz, Reinhard Macck, João Dias da Silveira e Alberto Ribeiro Lamego) para participar do XIX Congresso Internacional de Geologia, na Argélia.

Registra-se que nos primeiros anos do CNPq, as Ciências Geológicas ocuparam um lugar central no projeto nuclear empreendido pelo presidente Álvaro Alberto. Como já informado, as ciências nucleares foram aquelas que receberam 0 maior volume de recursos, provenientes estes do Fundo Nacional de Pesquisas e de uma verba especial aprovada pelo Congresso Nacional no valor de $\mathrm{Cr} \$ 20$ milhões. Dentre os setores de aplicação destes recursos estavam a prospecção geológica e a produção de urânio metálico. A presidência do CNPq teve inúmeras iniciativas que resultaram em investimentos diretos com o objetivo de realizar sondagem, estudo e prospecção de minerais radioativos; fazer levantamentos aerofotogramétricos; produzir urânio metálico; pesquisadores brasileiros, como o conselheiro do CNPq, Mário da Silva Pinto, foram enviados aos EUA para realizar estudos, dentre outros assuntos, sobre a monazita e terras raras, ${ }^{75}$ bem como pesquisadores estrangeiros vieram ao Brasil proferir palestras, a exemplo de F. Schumacher, da Universidade Bonn, sobre as jazidas uraníferas do Brasil; ${ }^{76}$ montar e construir aceleradores do tipo sincrociclotron para o CBPF. ${ }^{77}$

Nesses primeiros anos do CNPq, sob a presidência do cientista-militar Álvaro Alberto, foi intenso o investimento no levantamento das principais jazidas de materiais atômicos do país, salientando-se a busca para localizar terras-raras, urânio e tório, tal como para extrair e industrializar a monazita, materiais minerais atômicos estratégicos importantes 
para o desenvolvimento do programa nuclear brasileiro. Para se extrair e industrializar a monazita tais atividades foram realizadas por empresas de capital privado, e o Conselho adquiria toda a produção das empresas por força da Lei. Por sua vez, quanto à prospecção, pesquisa e obtenção de urânio e tório, o Departamento Nacional de Produção Mineral auxiliava o CNPq para a realização de levantamentos geológicos aéreos. ${ }^{78}$

A análise das atas permite afirmar que a maioria esmagadora dos beneficiados, no que tange à circulação internacional de pesquisadores, era do sexo masculino. São muito poucas as mulheres contempladas com algum tipo de fomento por parte do CNPq. Também não tinham assento no Conselho Deliberativo (CD), nem as funções de presidente das comissões do $\mathrm{CD}$ e de diretor das divisões técnico-científica. Entretanto, havia muitas mulheres cientistas trabaIhando nas principais instituições científicas brasileiras, e recebendo financiamento do Conselho, embora em menor escala que os homens.

Um exemplo a ser apresentado é o da trajetória da cientista Marta Vannucci. A carreira científica da pesquisadora foi incrementada pelo CNPq que concedeu à estudiosa, em setembro de 1955, uma bolsa de pesquisas que seria fundamental para a cientista prosseguir com os seus estudos sobre o plâncton (Processo n. 2.383/54, submetido pela pesquisadora Marta Vanucci solicitando uma bolsa de pesquisa - Ata n. 288, de 20 de outubro de 1955). A bolsa foi renovada no ano seguinte por mais dois anos (Ata n. 342, de 26/09/1956, Processo n. 2.383/54), e, no ano de 1958, após uma nova solicitação, a pesquisadora foi contemplada com mais uma renovação (Ata n. 432, de 23/07/1958, Processo n. 431/58).

A cientista Marta Vannucci também seria contemplada com outros tipos de auxílio pelo CNPq, como auxílio para viagem para o exterior (Ata n. 585, de 23/08/1961, Processo n. 3.212/61); solicitação de bolsa de aperfeiçoamento (Ata n. 704, de 18/12/1963, Processo n. 3.489/63); passagens e diárias (Ata n. 758, de 14/12/1964, Processo n. 5.185/64); auxílio para a realização de trabalhos de pesquisa na Seção de Plâncton (Ata n. 722, de 29/04/1964, Processo n. 6.119/63); auxílio não identificado (Ata n. 788, de 28/07/1965, Processo n. 3.792/65). A concessão de auxílios e bolsas por parte do Conselho à cientista mostra o prestígio que a mesma alcançara no cenário nacional. 0 CNPq teve, assim, um importante papel para incrementar a carreira da pesquisadora.

No ano de 1956, Marta deu um grande impulso à sua carreira enquanto cientista. Além de dar início às suas pesquisas sobre as hidromedusas das águas brasileiras, ela foi contemplada com uma bolsa concedida pela Unesco para ir realizar investigações na Estação de Biologia Marinha de Millport, na Escócia. Na ocasião, ela visitou importantes centros de estudo, de reputação internacional, como o Fishery Laboratory, de Aberdeen, e o Oceanographic Institute de Edinburgh, inteirando-se de métodos e técnicas de pesquisas modernas empregadas no estudo do plâncton.

Por seu turno, as instituições beneficiadas foram aquelas de tradição, plenamente institucionalizadas, no cenário nacional, como o Museu Nacional, e o Observatório Nacional, cujas atividades remontavam ao século XIX. A estas referidas somam-se as Faculdade de Filosofia, Ciências e Letras da Universidade de São Paulo, e da Universidade do Brasil; o Instituto Oswaldo Cruz; o Instituto Biológico de São Paulo; o Instituto Butantã; os Institutos Agronômicos de Campinas, do Estado de Minas Gerais, do Sul, São Paulo e do Nordeste; o Instituto Nacional de Tecnologia; o Centro Brasileiro de Pesquisas Físicas (CBPF), entre outros, espaços de produção de conhecimento que ocupavam um lugar central na tradição de pesquisa do movimento de institucionalização da ciência do pós-guerra. ${ }^{79}$

Além dessas instituições de tradição, e já consolidadas as suprarreferidas que recebiam apoio do Conselho, havia aquelas recém-criadas, como o Instituto Paulista de Oceanografia (IPO), que recebia bolsas e auxílios do CNPq. ${ }^{80}$

0 Instituto Paulista de Oceanografia (IPO) - Decreto-lei n. 16.685 de 31/12/1946, subordinado à Divisão de Proteção e Produção de Peixes e Animais Silvestres do Departamento de Produção Animal, da Secretaria de Agricultura) foi o primeiro instituto de Oceanografia criado no Brasil.

Competia ao IPO o estudo do relevo submarino da plataforma continental do Estado de São Paulo; o estudo dos fatores físicos, químicos, biológicos, que influem na produtividade das águas marinhas e continentais paulistas, igualmente nas causas de quaisquer outra natureza, que modifiquem suas condições; 0 estudo da flora e da fauna 
aquáticas, marítimas e interiores, e, em particular, das espécies de significação econômica e a racionalização da pesca e indústrias correlatas.

0 referido decreto de criação do IPO já o incluía como um dos institutos de pesquisa que concorriam para ampliar 0 ensino da Universidade de São Paulo (USP). ${ }^{81}$ Além disso, determinava que o mesmo teria uma sede própria, e seria composto pelos seguintes seções: Administrativa; de Oceanografia; de Hidrobiologia; de Fauna Marítima; de Biblioteca e Estatística; de Desenho e Fotocinematografia.

Uma mudança na competência do Instituto ocorreu mediante Decreto-Lei n. 16.916, de 14/02/1947, que atribuiu ao órgão a função do estudo da plataforma continental, dos fatores físicos, químicos e biológicos que influenciavam na produtividade do mar, bem como da flora e fauna marinhas, visando, principalmente, ao seu aspecto econômico.

Criado em fins de 1946, consoante referido anteriormente, o IP0 só iniciou efetivamente as suas atividades no último trimestre de 1948, embora o prosseguimento normal do seu funcionamento, sem paralisação alguma, só ocorresse a partir de janeiro de 1949. ${ }^{82}$ Logo, o IOP foi criado no contexto pós-segunda guerra mundial.

Os oceanos também se constituíram num elemento de preocupação dos dirigentes da referida agência internacional. Na 18 Sessão da Unesco em 1950, o diretor-geral autorizou a coordenação da pesquisa sobre problemas científicos relacionados aos oceanos e biologia marinha. No mesmo período, o Conselho Internacional para Ciência (ICSU) estabeleceu um Comitê Especial (mais tarde denominado Científico) sobre Pesquisas Oceânicas (SCOR). No primeiro encontro ocorrido no ano de 1957, o SCOR iniciou o planejamento para a realização de uma expedição internacional no Oceano Índico, concordando que a Unesco fosse a entidade copatrocinadora. Esses esforços de cooperação foram necessários para impulsionar os projetos científicos sobre os oceanos, especialmente em regiões onde existiam poucos recursos para apoiar os referidos projetos.

Em novembro de 1958, a Unesco tomou a decisão de convocar uma conferência intergovernamental sobre pesquisa oceanográfica. A Conferência Intergovernamental sobre Pesquisa Oceânica foi realizada em Copenhagen, na Dinamarca, no período de 11 a 16 de julho de 1960, na qual ficou determinado que uma Comissão Oceanográfica Intergovernamental (ICO) seria estabelecida com o apoio da Unesco. Essa recomendação foi adotada pela Resolução n. 231 na Conferência Geral da Unesco realizada no mesmo ano, juntamente com a aprovação dos estatutos iniciais e um Escritório de Oceanografia para atuar como a secretaria do ICO. A justificativa para o nascimento dessa nova e valiosa Organização das Nações Unidas (ONU) foi baseada na necessidade da cooperação científica para a pesquisa oceanográfica. ${ }^{83}$

Foi, portanto, nesse contexto pós-segunda guerra, quando cooperação, intercâmbios, convênios, comunicações eram palavras-chaves do momento, que o governo do Estado de São Paulo criou o IPO e trouxe um cientista estrangeiro para dirigi-lo, o russo Wladimir Besnard (1890, São Petersburgo, Rússia - 1960, São Paulo, Brasil) foi o cientista convidado para assumir a direção da nova instituição instalada na cidade de São Paulo. ${ }^{84}$

Besnard realizou pesquisas pioneiras no litoral paulista e em oceano aberto. Para a divulgação das pesquisas dos trabalhos dos pesquisadores do órgão foi criado o Boletim do Instituto de Oceanografia, no ano de 1950, primeiro periódico nacional na área de Oceanografia. 0 Boletim foi o principal veículo de divulgação de centenas de trabalhos científicos de autoria de docentes e pesquisadores do IOP e de membros da comunidade científica nacional e estrangeira.

Besnard foi o responsável pela instalação de duas bases de pesquisas oceanográficas nos extremos norte e sul do litoral paulista: uma em Cananeia, e a outra em São Sebastião.

A base de Cananeia foi um local de intensa visitação e de pesquisa científica. Diversos pesquisadores foram para a região de Cananeia realizar estudos científicos sobre essa área. As informações colhidas pelos estudiosos nessas viagens contribuíram para ampliar os conhecimentos sobre o mar e os elementos que o compunham. Muitas dessas informações foram disponibilizadas e difundidas em artigos publicados no Boletim do Instituto Paulista de Oceanografia, publicação que tinha como objetivo primordial divulgar as pesquisas no campo da oceanografia que estavam sendo realizadas no Brasil, e tinha o financiamento do CNPq. 


\section{Considerações finais}

Os primeiros anos do CNPq, na administração do presidente Álvaro Alberto, revelam o pesado investimento do órgão no tocante ao fomento de bolsas e auxílios para a promoção de circulação de cientistas nacionais e estrangeiros. Bolsas, viagens, congressos e reuniões, missões científicas, cursos de especialização, visitas a centros científicos e laboratórios de ponta, acolhimento de professores estrangeiros, entre outros, receberam uma atenção especial por parte do conselho. A cooperação científica internacional fazia parte da agenda do CNPq e tornou-se um objetivo a ser seguido.

Atento às profundas transformações que estavam se processando no cenário internacional, Álvaro Alberto se apropriou desses princípios e norteou as suas ações durante os anos da sua gestão. A internacionalização das ciências possibilitava as trocas entre as diversas sociedades e o enriquecimento comum entre os cientistas das várias nações. Um intenso movimento de ida de pesquisadores nacionais para o estrangeiro e de vinda de cientistas estrangeiros para o Brasil marcou esse momento inicial de funcionamento do Conselho, e revela que os ideais da Unesco de internacionalização da ciência pela cooperação científica estiveram presentes nos primeiros cinco anos de atividade do Conselho. Álvaro Alberto partilhava do entendimento difundido pela organização internacional de que a aplicação pacífica e racional da ciência permitiria novos desafios a serem cumpridos, tais como: combate à fome no mundo, 0 enfrentamento à explosão populacional, a cura de doenças, a extirpação à desertificação, a conservação dos recursos naturais, e a melhoria das condições de vida nos trópicos. Por meio da disseminação dos valores da ciência, realizada pelo investimento nas trocas e intercâmbios científicos, acreditava-se que seria possível promover o desenvolvimento do Brasil, erradicando os entraves que o impediam de equipará-lo ao mesmo patamar socio-econômico, cultural e científico dos ditos países desenvolvidos, e assim contribuir para o estabelecimento da paz mundial. Dessa forma, a ciência assumia uma função de esclarecimento e de promoção do bem-estar.

\section{Notas e referências bibliográficas}

Alex Gonçalves Varela é historiador, doutor em Ciências pela Unicamp, pós-doutor júnior UERJ-CNPq, bolsista PCI da CHC-MAST. E-mail: alexvarela@mast.br

Heloísa Maria Bertol Domíngues é historiadora, doutora em História pela USP, atual diretora do Museu de Astronomia e Ciências Afins (MAST).

E-mail: heloisa@mast.br

Carlos Alberto Quadros Coimbra é matemático, doutor em Engenharia Elétrica pela PUC-Rio, pesquisador-adjunto da CED-MAST.

E-mail: caqcoimbra@mast.br

1 A historiadora das ciências, Ana Maria Ribeiro de Andrade, no âmbito das relações internacionais, procurou analisar a atuação do Conselho com base na questão dos recursos minerais físseis, principalmente na relação Brasil-USA. ANDRADE, Ana Maria Ribeiro de. Físicos, mésons e política. A dinâmica da ciência na sociedade. São Paulo-Rio de Janeiro: HUCITEC/MAST/CNPq, 1999. Nosso objetivo será outro no plano das relações científicas internacionais: observar a atuação empreendida pelo cientista-militar Álvaro Alberto para a questão da circulação internacional de cientistas.

2 BOSCHI, Caio. César. A Universidade de Coimbra e a formação intelectual das elites mineiras coloniais. Estudos Históricos. Rio de Janeiro, v. 4, p. 100-111, 1991; CARVALHO, J. M. A construção da ordem/teatro de sombras. 2. ed. Rio de Janeiro: RELUME DUMARA, 1996.

3 FIGUEIRÔA, Silvia Fernanda de Mendonça. A formação das ciências geológicas no Brasil: uma história social e institucional. São Paulo: HUCITEC, 1997.

4 LOPES, Maria Margaret. O Brasil descobre a pesquisa científica: os museus e as ciências naturais no século XIX. 1. ed. São Paulo: HIUCITEC, 1997; SANJAD, Nelson. Emílio Goeldi (1859-1917): aventura de um naturalista entre a Europa e o Brasil. Rio de Janeiro: EMC Edições, 2009.

5 LOPES, Maria Margaret. Os intercâmbios dos museus latino-americanos relacionados às ciências geológicas na transição para o século XX. Quipu. México, v. 12, n. 1, p. 43 e 47, jan.-abr. 1999.

6 PEREIRA, Margareth da Silva (Org.). 1908, um Brasil em exposição. Rio de Janeiro: Casa Doze, 2010.

7 DOMínGUES, H. M. B. de. As demandas científicas e a participação do Brasil nas exposições internacionais do século XIX. Ouipu. México, v. 12, n. 2, p. 207, maio-ag. 1999. p. 207.

8 FARIA, Lina Rodrigues de. A Fundação Rockefeller e os serviços de saúde em São Paulo (1920-30): perspectivas históricas. História, Ciências, Saúde - Manguinhos. Rio de Janeiro, v. 9, n. 3, p. 561-590, 2002.

9 ALMEIDA, M. Circuito aberto: ideias e intercâmbios médico-científicos na América Latina nos primórdios do século XX. História, Ciências, Saúde Manguinhos. Rio de Janeiro, v. 13, p. 733-757, 2006.

10 DANTES, Maria Amélia Mascarenhas; HAMBURGUER, Amélia Império. A ciência, os intercâmbios e a História da Ciência: reflexões sobre a atividade científica no Brasil. In: HAMBURGUER, Amélia Império et al. (Org.). A ciência nas relações Brasil-França (1850-1950). São Paulo: EDUSP/FAPESP, 1996. 
11 PETITJEAN, Patrick. As missões universitárias francesas na criação da Universidade de São Paulo (1934-1940). In: HAMBURGUER, Amélia Império et al. (Org.). A ciência nas relações Brasil-França (1850-1950). São Paulo: EDUSP/FAPESP, 1996.

12 MOTOYAMA, S. A gênese do CNPq. Revista da Sociedade Brasileira de História da Ciência. Rio de Janeiro, n. 2, p. 28, jul.-dez. 1985.

13 Id., ibid., p. 32; DOMínGUES, H. M. B.; PETITJEAN, P. A Unesco, o Instituto Internacional da Hiléia Amazônica e a Antropologia no final dos anos 1940. In: FAULHABER, P.; TOLEDO, P. M. (Ed.). Conhecimento e Fronteira: História da Ciência na Amazônia. Belém: Museu Paraense Emílio Goeldi, 2001. p. 82.

14 MOTOYAMA, op. cit., p. 35.

15 Sobre o IBECC ver: ABRANTES, Antonio Carlos Souza de; AZEVEDO, Nara. 0 Instituto Brasileiro de Educação, Ciência e Cultura e a Institucionalização da Ciência no Brasil, 1946-1966. Boletim Museu Paraense Emílio Goeldi. Ciências Humanas. Belém, v. 5, n. 2, p. 474, 2010.

16 DOMINGUES; PETITJEAN, op. cit., p. 83; MAIO, Marcos Chor. A tradução local de um projeto internacional: a Unesco, o CNPq e a criação do Inpa. In: FAULHABER, Priscila et al. (Ed.) Conhecimento e fronteira: história da ciência na Amazônia. Belém: Museu Paraense Emílio Goeldi, 2001. p. 57-58.

17 DOMINGUES; PETITJEAN, ibid., p. 84.

18 Para Ana Maria Ribeiro de Andrade, o personagem Álvaro Alberto era apenas um militar fazendo política científica. Contudo, no nosso ponto de vista, ele era mais do que um representante das Forças Armadas. (ANDRADE, Ana Maria Ribeiro de. Físicos, mésons e política. A dinâmica da ciência na sociedade. São Paulo-Rio de Janeiro: HUCITEC/MAST/CNPq, 1999. p. 46). Em sua trajetória de vida, as faces de militar, cientista, acadêmico e empresário são indissociáveis, devendo ser analisadas de forma integrada e conjunta, e não dissociadas. Sua trajetória de vida revela a atuação ativa em diversos campos da ciência, como a química, na qual publicou diversos escritos acadêmicos e foi empresário no setor produtivo; a energia nuclear, envolvendo-se em ampla discussão sobre o fenômeno atômico e nuclear no contexto do pós-guerra; a filosofia e a história das ciências, tendo publicado inúmeros artigos sobre 0 tema. Participou ativamente de sociedades científicas, tais como a Academia Brasileira de Ciências e o Instituto Histórico e Geográfico Brasileiro. Na função de empresário criou a Sociedade Brasileira de Explosivos Rupturita, que atendeu especialmente à demanda de explosivos para mineração. Nessa linha está a obra de S. Motoyama e J. Garcia, que buscou retratar o personagem a partir de uma análise associada de suas múltiplas facetas (MOTOYAMA, S.; GARCIA, J. C. V. (Org.). 0 almirante e o novo Prometeu. Álvaro Alberto e a C\&T. São Paulo: Editora Unesp; Centro Interunidade de História da Ciência, 1996.)

19 DOMínGUES, H. M. B. Da razão do poder ao poder da razão: o lugar social das ciências, no Brasil, em meados do século XX. In: PIETROCOLA, Maurício; FREIRE Jr., Olival (Org.) Filosofia, Ciência, e História: uma Homenagem aos 40 anos de colaboração de Michel Paty com o Brasil. São Paulo: FAPESP; Discurso Editorial, 2005. p. 378; MOTOYAMA, S. Álvaro Alberto e a Energia Nuclear. In: MOTOYAMA, S.; GARCIA, J. C. V. (Org.) 0 almirante e o novo Prometeu. Álvaro Alberto e a C\&T. São Paulo: Editora Unesp; Centro Interunidade de História da Ciência, 1996. p. 67.

20 DOMínGUES, H. M. B. Darwinismo na Unesco: Paulo Carneiro, Julian Huxley e o Projeto do IIHA (1946-1950). In: DOMíngUES, H. M. B. et al. (Org.). Darwinismo, meio ambiente, sociedade. São Paulo: Via Lettera; Rio de Janeiro: MAST, 2009. p. 272.

21 DOMínGUES, H. M. B.; PETITJEAN, P. A redescoberta da Amazônia num projeto da Unesco: o Instituto Internacional da Hiléia Amazônica. Estudos Históricos. Rio de Janeiro, v. 14, n. 26, p. 269, 2000.

22 PETITJEAN, Patrick. Introduction: Visions and revisions. Defining Unesco's scientific culture, 1945-1965. In: PETITJEAN, P.; ZHAROV, V.; GLASER, G.; RICHARDSON, J.; DE PADIRAC, B.; ARCHIBALD, G. (Ed.). Sixty years of Science at Unesco - 1945-2005. Paris: Unesco, 2006. p. 29.

23 ELZINGA, Aant. A Unesco e a política de cooperação internacional no campo da ciência. In: MAIO, Marcos Chor. (Org.) Ciência, política e relações internacionais. Ensaios sobre Paulo Carneiro. Rio de Janeiro: Editora FIOCRUZ e Unesco, 2004. p. 106.

24 MAIO, Marcos Chor. Demandas globais, respostas locais: a experiência da Unesco na periferia no pós-guerra (1946-1952). In: MAI0, Marcos Chor. (Org.) Ciência, política e relações internacionais, op. cit., p. 147.

25 ELZINGA, op. cit., p. 110.

26 Id., ibid., p. 110

27 ANDRADE, A. M. R. de. Valores e ideias presentes nas fundações do CBPF e CNPq. In: TROPER, Amós et al. (Org.). Os 60 anos do CBPF e a gênese do CNPq. Rio de Janeiro: CBPF, 2010. p. 51.

28 DOMÍNGUES, Heloísa Maria Bertol. Da razão do poder ao poder da razão: o lugar social das ciências, no Brasil, em meados do século XX. In: PIETROCOLA, Maurício; FREIRE JR., Olival (Org.) Filosofia, ciências e história: uma homenagem aos 40 anos de colaboração de Michel Paty com o Brasil. São Paulo: FAPESP; Discurso Editorial, 2005. p. 385.

29 Informa-se que, em 14 de julho de 1946, realizou-se a sessão inaugural da CEA e nela foi apresentado, pela delegação norte-americana, um plano de controle da energia atômica - Plano Baruch. 0 projeto de um órgão internacional de controle da energia atômica foi saudado pelo representante brasileiro, Álvaro Alberto, como uma iniciativa admirável. Por mais que alinhado aos EUA, a representação brasileira fez restrições ao Plano Baruch por considerar que este atingia os interesses econômicos do país. Alberto exigia quotas preferenciais de energia e a opção por lugares para a instalação de reatores. 0 Brasil pleiteava a instalação desses reatores em seu território.

30 Conferir DOMÍNGUES, op. cit., 2005; MOTOYAMA; GARCIA, op. cit., 1996.

31 MOTOYAMA, S. Prelúdio para uma História. Ciência e tecnologia no Brasil. São Paulo: Editora da Universidade de São Paulo, 2004; GOMES, Angela Maria de Castro (Org.). Vargas e a crise dos anos 50. Rio de Janeiro: Relume Dumará, 1994.

32 Dentre esses cientistas estavam Álvaro Alberto, o responsável por presidir a comissão redatora do anteprojeto do Conselho (1949) e o primeiro presidente da instituição; Carlos Chagas Filho (chefe do Setor de Pesquisas Biológicas); Olympio Ribeiro da Fonseca Filho (membro do primeiro conselho deliberativo); Joaquim Costa Ribeiro (membro do primeiro conselho deliberativo, e diretor-geral da Divisão Técnico-Científica); Lélio Gama (membro do primeiro conselho deliberativo, e chefe da Comissão de Ciências Físicas e Matemáticas), entre outros. DOMínGUES, H. M. B.; PETITJEAN, P. A Unesco, o Instituto Internacional da Hiléia Amazônica e a Antropologia no final dos anos 40. In: FAULHABER, P.; TOLEDO, P. M. (Ed.). Conhecimento e fronteira: história da ciência na Amazônia. Belém: Museu Paraense Emílio Goeldi, 2001. p. 85.

33 ANDRADE, Ana Maria Ribeiro de. Físicos, mésons e política. A dinâmica da ciência na sociedade. São Paulo-Rio de Janeiro: HUCITEC/MAST/CNPq, 1999.

34 Apud ABRANTES, Antonio Carlos Souza de; AZEVEDO, Nara. 0 Instituto Brasileiro de Educação, Ciência e Cultura e a Institucionalização da Ciência no Brasil, 1946-1966. Boletim Museu Paraense Emílio Goeldi. Ciências Humanas. Belém, v. 5, n. 2, p. 474, 2010. 
MAIO, M. C.; SÁ, M. R. Ciência na periferia: a Unesco, a proposta de criação do Instituto Internacional da Hiléia Amazônica e as origens do INPA. História, Ciências, Saúde - Manguinhos. Rio de Janeiro, v. 6, p. 985, 2000.

36 DOMínGUES, H. M. B.; PETITJEAN, P. A redescoberta da Amazônia num projeto da Unesco: o Instituto Internacional da Hiléia Amazônica. Estudos Históricos. Rio de Janeiro, v. 14, n. 26, p. 265-292, 2000.

37 LARSEN, Knud. Los servicios bibliográficos nacionales. Paris: Unesco, 1955, p. V.

38 ELZINGA, op. cit., p. 112.

39 DUFOUR, Franck. Calculated risks. Initiatives in pure and applied mathematics. In: PETITJEAN, P.; ZHAROV, V.; GLASER, G.; RICHARDSON, J.; DE PADIRAC, B.;ARCHIBALD, G. (Ed.). Sixty years of science at Unesco 1945-2005. Paris: Unesco, 2006, p. 104.

40 ALMEIDA, A. M. F.; CANÊDO, L. B.; GARCIA, A.; BITTENCOURT, A. B.. Circulação Internacional e Formação Intelectual das Elites Brasileiras. Campinas: Ed. da Unicamp, 2004.

41 ALBAGLI, Sarita. Marcos institucionais do Conselho Nacional de Pesquisas. Perspicillum. Museu de Astronomia e Ciências Afins. Rio de Janeiro, vol. 1, n. 1, maio de 1987, p. 50.

42 De acordo com Ana Maria Ribeiro de Andrade, o fim da era Vargas coincidiu com a perda da sustentação política de Álvaro Alberto no CNPq. Sem condições de resistir às pressões da corrente liderada pelo general Juarez Távora, chefe do Gabinete Militar da Presidência da República - a favor da política de alinhamento incondicional aos Estados Unidos - e candidato a presidente pela UDN. Além desse fato, nesse ambiente de tensão, acentuaramse outras diferenças entre os conselheiros do CNPq, especialmente com relação à questão da energia nuclear. Ver: ANDRADE, Ana Maria Ribeiro. Opção nuclear. 50 anos rumos à autonomia. Rio de Janeiro: MAST, 2006, p. 59.

43 Id, Ibid., p. 98.

44 ANDRADE, Ana Maria Ribeiro de. Físicos, mésons e política, op. cit.

45 Quanto às bolsas foram instituídas as seguintes categorias: a) bolsas no país: de iniciação científica; de aperfeiçoamento ou especialização; de estágio para desenvolvimento técnico; de pesquisador assistente; de pesquisador associado; e de chefe de pesquisas; b) bolsas no exterior; de especialização ou de pesquisa; de aperfeiçoamento técnico. Quanto aos auxílios foram instituídas as seguintes categorias: Aquisição de material de pesquisa científica; contrato de serviços de natureza técnica ou especializada; aquisição de livros, periódicos e coleções científicas; contrato de pesquisadores; participação de pesquisadores em congressos científicos; congressos, expedições científicas, publicações. ALBAGLI, op. cit..

46 Utilizamos as Atas do Conselho Deliberativo do CNPq no período de 1951 a 1956, todas sob a guarda do Arquivo do Museu de Astronomia e Ciências Afins.

47 Este artigo é uma tentativa preliminar de apresentar os primeiros levantamentos sobre a circulação internacional dos cientistas nos primeiros anos de funcionamento do CNPq. Ainda não temos como contabilizar de forma precisa quantos brasileiros conseguiram auxílios e bolsas de estudo para ir estudar no exterior, nem apresentar informações sobre os temas dos projetos e as suas respectivas áreas acadêmicas. A documentação sobre a concessão de auxílios e bolsas nos primeiros anos do CNPq é bastante lacunar. As nossas fontes principais são as Atas e os Anais das Reuniões do Conselho Deliberativo do CNPq. Estas fontes apresentam informações sobre a concessão de auxílios e bolsas a pesquisadores, apresenta o número do processo, mas não informa sobre 0 conteúdo do mesmo. Assim, não temos como obter informações sobre os temas dos projetos e as suas respectivas áreas por meio das fontes referidas. 0 ideal seria a consulta ao processo propriamente dito, no entanto, os mesmos não se encontram no Arquivo de História da Ciência localizado no MAST. As mesmas considerações são válidas para se contabilizar o número de cientistas estrangeiros que para cá vieram no mesmo período.

48 Sobre a formação do CD do CNPq e a atuação de Álvaro Alberto nessas reuniões conferir também: ANDRADE, A. M. R. de. Físicos, mésons e política..., op. cit., p. 115-118.

49 ANDRADE, Ana Maria Ribeiro de. Os raios cósmicos entre a ciência e as relações internacionais. In: In: MAIO, Marcos Chor. (Org.) Ciência, política e relações internacionais. Ensaios sobre Paulo Carneiro. Rio de Janeiro: Editora FIOCRUZ e Unesco, 2004. p. 225.

50 ANDRADE, A. M. R. de. Físicos, mésons e política..., op. cit., p. 125 e 132-138.

51 No caso de dez bolsistas, não há a informação precisa sobre o destino do beneficiado para o país europeu onde ia desenvolver os seus estudos. Aparece apenas a referência Europa.

52 Ver os quadros 20 e 21 do livro de Ana Maria R. de Andrade..., op. cit., p. 124

53 Anais do Conselho Deliberativo do CNPq. Sessão 319, 26/04/1956, p. 29. Loc.: Arquivo do Museu de Astronomia e Ciências Afins.

54 Anais do Conselho Deliberativo do CNPq. Sessão 320, 27/04/1956, p. 2. Loc.: Arquivo do Museu de Astronomia e Ciências Afins.

55 Anais do CNPq. 319a Sessão do Conselho Deliberativo do CNPq realizada a 26 de abril de 1956, p. 29.

56 Id., ibid., p. 29; Anais do CNPq. 320ª Sessão do Conselho Deliberativo do CNPq realizada a 27 de abril de 1956, p. 3.

57 Id., ibid., p. 29.

58 Id., ibid., p. 30.

59 Id., ibid., p. 30.

60 Id., ibid., p. 30.

61 Anais do CNPq. 320 Sessão do Conselho Deliberativo do CNPq..., op. cit., p. 2.

62 KOHLER, Robert E. Landscapes, Labscapes. Exploring the lab-field border in Biology. Chicago and London: The University of Chicago Press, 2002 . p. 56.

63 AFONSO, J. C.; SANTOS, N. P. dos. Instituto de Química da UFRJ. 50 anos. Rio de Janeiro: Instituto de Química da UFRJ, 2009.

64 GARCIA, Afrânio. Vantagens e armadilhas do atraso. Estudos internacionais e recomposição das elites dirigentes no Brasil em perspectiva comparada. In: CANÊDO, Letícia et al. (Org.) Estratégias educativas das elites brasileiras na era da globalização. São Paulo: Fapesp; HUCITEC Ed., 2013. p. 191.

65 Id., ibid., p. 195.

66 Dentre os diversos cientistas estrangeiros que para cá vieram aparecem Paul Halmos; Keynes; Wilfred C. Parkinson; Zoltan Ovary; Tominouske Katsurai; 
Albert Portvin; Ralph Schiller; George A. Edwards; Grassé; Paul Kubelka; Peter Ulrich Heynemann; Pierre Casal; George L. Brown; Harold Edgard Strang; Manfred M. Mayer; Kurt Sitte; J. E. Vigier; Hans Goldmann; Olof H. Odman; Raymond Chaminade; Wilfrid C. Parkinson; Hans Limburg; Antoine Edmond Brum; Hans E. W. Zocher; M. M. Mayer; René Fauvert; John Marquis Converse; Carl Withers; J. H. Haynor; Collie; Charity Crocker; Izaak Kolthoff; G. Graillor Simpon; Gerhard Heinrich Dieke; Lecomte; Flavio Rezende; Laidlaw; Michel Dupuy; H.V. Hajek; Guzman Baron; Strugger; Arthur Aron; Gunther Kegek; Kathe Schwarz; Siegfried Stugger; Jacek Piotr Gorecki; Dieke; Lecomte; Hunter House; Richard Krausel; Gerard Hepp; Alexis Guerbilsky; Paul Harteck; Richard Klar; Roger Godement; Isidor I. Rabi; H. L. Anderson; John Marshall; Leona Marshall; Leon Denivelle; Leroy Schwarz; Cecil Hall; Maurice Françon; Mauricio Willkins; Frey Wislling; Ane Marie Staub; Gehard Strauss, dentre outros.

67 Dentre os cientistas financiados pelo CNPq para participar de congressos internacionais, nos diversos ramos do conhecimento, aparecem: no campo da Química, Quintino Mingoja participou do III Congresso Internacional de Química e da XVI Conferência da União Internacional de Química; no campo da Bioquímica, George Brooks, José Moura Gonçalves, José Almeida da Silva, e José Perrone participaram do II Congresso Internacional de Bioquímica, realizado em Paris; no campo da Física, Bernhard Gross participou do II Encontro Internacional de Reologia, e do Congresso de Física, ambos na Alemanha, e Hans Stammreich participou do Congresso Internacional de Espectrografia Molecular; Leandro Vettori participou do Simpósio de Fertilizantes Fosfatatos, nos EUA; Odette Zardetto de Toledo participou do VIII Congresso Internacional de Viticultura e Enologia, em Santiago do Chile, e da 36a Sessão Plenária do Comitê de L'office International du Vin, em Mendonza; Fany Malin Tchaicowsky participou do Seminário Inter-americano promovido pelo OEA, dentre outros.

68 Como exemplos, Luiz Cintra do Prado, Francisco J. Maffei, Hervásio Guimarães de Carvalho, e Carlos Chagas Filho, para realizar visitas a diversas instituições de pesquisa nos EUA, Canadá, e Europa, no período de janeiro a julho de 1952; viagem de Heitor Vinícius da Silveira Grillo a instituições de pesquisas agronômicas na Índia e Europa, no ano de 1953; viagem de Carlos Arnaldo Krug, como delegado do CNPq à $3^{\text {a }}$ Reunião Latino-Americana de Fitogeneticistas, Fitopatologistas e Edafólogos, em Bogotá, e para visitar estações experimentais na Indonésia, Malásia, e Índia; viagem de Álvaro Barcelos Fagundes, para visitar instituições européias devotadas à investigação agrícola, dentre outros.

69 Como exemplos, viagem de estudos à Inglaterra realizada por Guido Beck, e Manoel da Frota Moreira; viagem de estudos ao Canadá, por Hugo Caire de C. Faria, e Lagden Cavalcanti; viagem de estudos ao Chile, por Herman Lent, e Quintino Mingóia; viagem de estudos à Alemanha, por Antônio Sesso, José Menezes, e Silvano Raia; viagem de estudos ao México, por Ivan Dowsley Correia de Amorim, e Afrânio do Amaral; viagem de estudos aos EUA, por Carlos Pires Ferreira, Aida Espínola, José Augusto Deslandes, Milton Anacleto de Souza Vieira, Armando Duarte Costa, Ralph Schiller, Narzy Maia, Francisco de Assis Magalhães Gomes, Paulo Emílio de Freitas Barbosa, João de Mello Rezende, Jorge Bandeira de Mello, Márcio Otávio Agnese, José de Noronha Peres, Marcello de Camargo, Aristides Azevedo Pacheco Leão, Irajá Domiani Pinto, Saab Abud, Aníbal da Silveira, Maurício da Rocha e Silva, Hernani Coutinho da Costa, Lagden Cavalcanti, José Raimundo A. Ramos, Luiz Carlos de Souza Bittencourt, Ernesto Mendes Júnior, e Eduardo Enéas Galvão, Rubem Landeiro; viagem de estudo à Europa, por Antônio de Oliveira Fabrino, Orlando Rangel Sobrinho, Paulo Sá, Carlos Arnaldo Krug, Henrique da Rocha Lima, Hans Albert Meyer, Paulo Saraiva de Toledo, Maurício da Rocha e Silva; viagem de estudos à Bogotá (Colômbia), por Amaro Lanari Junior; viagem de estudos à França, por Joaquim Roberto C. Freire, Isaac Milder, Joana Nahuys, Harold Edgard Strang, Jandira Planet do Amaral; viagem de estudos a Roma (Itália), por Gleb Wataghin; viagem de estudos à Suíça, por Hansueli Burkhard, e Enio Ravaglia, dentre outras.

70 Como exemplo, a viagem de Bernhard Gross aos EUA, Alemanha e Inglaterra para a realização de pesquisas e conferências, dentre outros.

71 Mário Taveira representou o CNPq no II Congresso Luso-espanhol de Farmácia; Olympio da Fonseca representou o CNPq no Simpósio Sobre Doenças Produzidas por Fungos, na Califórnia, dentre outros.

72 Auxílio para a assinatura de revistas científicas estrangeiras, como o auxílio concedido à Universidade de São Paulo (USP) para conseguir a aquisição da revista "Neus fur Mineralogie, Geologie und Paleontologie"; como o auxílio concedido também à USP para adquirir obras de autores de relevo no campo das ciências, como a aquisição da obra de Humboldt e Bonpland denominada "Voyages aux Régions Equinoxiales du Nouveau Continent dans les Années 1799-1825".

73 Como exemplo a aquisição, nos EUA, de um coletor automático para cromotografia de coluna e trocas iônicas, cujo beneficiado foi José Moura Gonçalves, da Universidade do Brasil; auxílio para aquisição de aparelhagem nos EUA, solicitado por Deolindo Couto, do Instituto de Neurologia da Faculdade de Medicina da Universidade do Brasil, dentre outros.

74 Ainda estamos em processo de levantamento e quantificação das instituições científicas para onde os cientistas brasileiros estavam indo realizar 0 seu doutorado ou estagiar em laboratórios.

75 Relatórios de viagem de estudos do conselheiro Mário da Silva Pinto aos EUA, incluindo os assuntos: chuva artificial, produção de ácido sulfúrico, mineração de carvão, monazita e terras-raras, pesquisa científica e tecnológica na indústria. Rio de Janeiro, 24 de novembro de 1953. Loc.: Arquivo CNPq. Museu de Astronomia e Ciências Afins. CNPq T.1.2.012.

76 Relatório de F. Schumacher, da Universidade de Bonn, sobre jazidas uraníferas do Brasil. Rio de Janeiro, 17 de julho de 1954. Loc.: Arquivo CNPq. Museu de Astronomia e Ciências Afins. CNPq T.3.3.005

77 ANDRADE, Ana Maria Ribeiro de. Físicos, mésons e política... op. cit., p. 135-137.

78 Id. A opção nuclear. 50 anos rumos à autonomia. Rio de Janeiro: MAST, 2006. p. 55.

79 SCHWARTZMANN, Simon. Formação da comunidade científica no Brasil. Rio de Janeiro: Finep/Cia. Editora Nacional, 1979.

800 Instituto Paulista de Oceanografia (IPO) solicitou auxílio para despesas de excursão, manutenção das embarcações, aquisição de material de consumo, e publicação do boletim do instituto, além de duas bolsas de estudo (Processo n. 394/51, registrado na Ata n. 47 da Reunião do CD de 19/11?1951). 0 processo foi deferido com indicação de duas bolsas para licenciados e auxílio à publicação de seu boletim, tendo sido disponibilizado 0 valor de Cr\$ 200mil, aprovado na data de 04 de fevereiro de 1952, conforme aparece na Ata da Sessão de n. 64. Com a incorporação do IPO à USP, e a modificação do seu nome para Instituto Oceanográfico da Universidade de São Paulo (IO-USP) vários outros processos solicitados pelo Instituto e por seus pesquisadores foram deferidos: aprovação do Processo n. 357/52 (Ata n. 95 de 19/06/1952); renovações dos Processos n. 394/51, e 357/52, (Ata n. 166 em data de 25/08/1953); aprovação do Processo n. 394/51, (Ata n. 173 em data de 29/09/1953); processo 2383/54 submetido pela pesquisadora Marta Vanucci solicitando uma bolsa de pesquisa (Ata n. 288 de 20/10/1955); Processo n. 2234/54 (Ata n. 297 de 03/12/1955); Processo n. 2348/56 solicitando 2 (duas) bolsas para universitários, e auxílio para transporte de pessoal, e aquisição de material (Ata n. 329 de 22/06/1956); solicitação de bolsa de pesquisa por Maria Helena de Araújo Andrade (Processo n. 2113/53, Ata n. 338 de 29/08/1956); renovação do Processo n. 2383/54 (Ata n. 342 de 26/09/1956). Registra-se que, com o auxílio do CNPq, o IOUSP recebeu o professor estrangeiro F. C. Müller-Melchers (processo 3162/56, Ata n. 343 de 27/09/1956), que realizou pesquisas sobre as diatomáceas do plâncton marinho dos Estados de S.Paulo e R.G. do Sul (conferir o artigo publicado no Boletim do Instituto 
Oceanográfico, v. 6, n. 1-2, 1955).

81 A incorporação ocorreu por meio da Lei n. 1310, de 04/12/1951, com a denominação de Instituto Oceanográfico, passando a ser uma unidade de pesquisa da USP (IO-USP).

82 BESNARD, W. Apresentação. Boletim do Instituto Paulista de Oceanografia. São Paulo, v. 1, n. 1, p. 01, jun. 1950.

83 HOLLAND, G.. Observing and understanding planet ocean. A history of Intergovernmental Oceanography Comission (IOC). In: PETITJEAN, P.; ZHAROV, V.; GLASER, G.; RICHARDSON, J.; DE PADIRAC, B.; ARCHIBALD, G. (Ed.). Sixty years of science at Unesco 1945-2005. Paris: Unesco, 2006, p. 332-333.

84 As informações biográficas sobre o cientista Wladimir Besnard estão baseadas na obra: UNIVERSIDADE DE SÃO PAULO. INSTITUTO OCEANOGRÁFICO. Homenagem aos 120 anos de nascimento e 50 anos de falecimento do prof. Wladimir Besnard. São Paulo: Comissão de Memória do IO-USP, 2011.

[Recebido em Fevereiro de 2013. Aprovado para publicação em Abril de 2013] 